\title{
p53 immunohistochemistry can identify bronchial dysplastic lesions proceeding to lung cancer: a prospective study
}

\author{
A. Ponticiello ${ }^{+}$E. Barra*, U. Giani**, M. Bocchino ${ }^{+}$, A. Sanduzzi ${ }^{+}$
}

p53 immunohistochemistry can identify bronchial dysplastic lesions proceeding to Lung Cancer: a prospective study. A. Ponticiello, E. Barra, U. Giani, M. Bocchino, A. Sanduzzi. (C) ERS Journals Ltd 2000.

ABSTRACT: Dysplasia is an important step in bronchial carcinogenesis and smokers present more dysplastic lesions than nonsmokers. These lesions not always lead to malignancy, so there is a need for additional, preferentially objective, diagnostic markers.

To verify whether immunohistochemical overexpression of $\mathrm{p} 53$ protein in dysplastic areas could be a predictive marker of the development of lung cancer, we investigated p53 overexpression in 22 bronchial dysplastic lesions obtained by fibrebronchoscopy from heavy smokers who were not diagnosed as having lung cancer and were followed for a 4-yr period.

Nine $(41 \%)$ lesions showed p53-positivity. Seven lung cancers $(\mathbf{7 8 \%})$, mostly squamous cell carcinomas, were detected within the follow-up in these patients and 3 in $\mathbf{1 3}$ (23\%) patients with p53-negative lesions. Lung cancer occurred in all seven patients with dysplastic lesions showing $>10 \%$ p53 positive nuclei. The positive predictive value of 553 immunostaining for lung cancer was $78 \%$. The negative predictive value of p53 was $77 \%$. p53 staining was not detected in squamous metaplasia lesions without atypia and in normal bronchial epithelium.

Our findings provide evidence that p53-overexpression in bronchial dysplastic areas may be a clinically useful marker for identifying patients proceeding to, at least, squamous cell carcinoma and, in addition, may facilitate the detection of occult tumours.

Eur Respir J 2000; 15: 547-552.

Worldwide, lung cancer (LC) is the most common cancer in males and the incidence among females continues to increase in developed countries [1]. The role of smoking as the most important cause of LC is undeniable. The likelihood of developing $\mathrm{LC}$ is directly related to the number of cigarettes smoked over time (usually quantified as the number of pack-years ): 20-30 pack-yrs (one pack-yr is defined as the equivalent of smoking one pack per day for one year) is now considered the threshold for an increased risk of developing LC and the onset of smoking at a young age is a particularly strong risk [2].

The histological changes associated with the development of LC consist of basal-cell hyperplasia, squamous metaplasia (SM), dysplasia and carcinoma in situ and the number of SM lesions, as well as the grade of dysplasia, increases with the number of cigarettes smoked [3-5]. This sequence is most evident in squamous cell carcinoma (SQCC) which derives directly from bronchial epithelial cells, but it is not as clear in the other types of LC [3-6]. Progression is not inevitable as the risk of LC seems to decline with the cessation of smoking and the reversible nature of SM lesions, even with high grade of dysplasia, has been suggested [4,6-8]. Therefore, morphological methods are not always sensitive enough to identify those lesions which may progress to malignancy.

The evolution of LC, especially of SQCC, has been studied using the genetic model proposed for colorectal tumorigenesis in which the multistage process of carcino-
${ }^{+}$Institute of Thoracic Diseases, University "FedericoII" of Naples, Italy. *Pathology Service, Hospital "D. Cotugno", Naples, Italy. **Dept of Public Health, University "FedericoII" of Naples, Italy.

Correspondence: D.A. Ponticiello

Via P. Castellino no. 128

80131 Naples

Italy

Fax: 390817702457

Keywords: Bronchial dysplasia immunohistochemistry lung cancer p53

Received: March 61999

Accepted after revision December 301999 genesis has been deciphered as a progressive accumulation of gene mutations (activation of cellular proto-oncogenes and inactivation of tumour-suppressor genes) that are thought to accompany the morphological changes that precede malignancy [9-10].

So far, the best known tumour suppressor gene is the p53 gene located at position 13 on the short arm of chromosome 17, which encodes a $53 \mathrm{kDa}$ nuclear phosphoprotein. p53 gene and gene product are involved in cell growth control by stimulating the expression of downstream genes that negatively control cell growth: when cellular DNA are damaged, the cells increase the levels of wild-type p53 protein that switch off the cell cycle until damage is repaired or trigger cell suicide through apoptosis [11-13]. Loss of this activity, by mutations in the proteincoding sequence of the gene, may lead to neoplastic transformation [13, 14-15].

Mutations prolong the half-life of the $\mathrm{p} 53$ protein, so mutant protein accumulates within the nuclei of malignant cells in amounts that can be detected by immunohistochemistry, whereas the concentration of the wild-type p53 in normal cells is so low that it cannot be detected immunohistochemically.

Previous studies have provided evidence that lesions in the p53 gene is an early event in the development of lung cancer, at least of SQCC, and the overexpression of p53 may be helpful in the identification of those early lesions which progress to malignancy $[12,16-26]$. Besides, p53 
overexpression has also been observed in premalignant lesions associated with other tobacco-related tumours including head, neck and oesophageal squamous cell cancer [23]. SuZUKi et al. [24] showed that lifetime cigarette consumption (thirty pack-years) was the only factor closely related to p53 mutations and it has also been reported that the type of mutation seems to reflect the mutagens involved: GC to TA transversions, frequently found in LC, are usually caused by benzpyrene contained in cigarette smoke [13-15, 24].

However, these studies mostly investigated p53 overexpression in metaplastic lesions adjacent to invasive SQCC. They did not analyse p53-positive metaplastic areas from subjects without LC or did not report the evolution of these lesions in a clinical follow-up. Therefore, a clinical prospective study was undertaken to determine whether immunohistochemical overexpression of p53 in bronchial dysplastic areas, collected by fibrebronchoscopy from subjects without a detectable LC at the time biopsies were taken, could be a more predictive marker for the development of LC than dysplasia.

\section{Materials and methods}

\section{Case selection}

Of the patients who underwent a fibrebronchoscopy between 1993 and 1994 in the authors' institute due to the clinical and radiological suspicion of LC, multiple biopsies were performed in subjects who had a history of smoking for $\sim 30$ pack-yrs to obtain tissue that was screened for SM and graded for dysplasia. The cases diagnosed as having LC by bronchoscopy, transthoracic needle aspiration biopsy (TNAB) or surgical resection were excluded from the study.

Biopsy specimens. The biopsy specimens were taken from four standardized sites: the bifurcation of the right upper lobe and main stem, the bifurcation of the right middle lobe and lower lobe, the medial basal bronchus of the right lower lobe, the bifurcation of the left upper lobe and lingula [3].

Histological criteria and classification of lesions. The specimens were independently examined for the presence of SM and graded for dysplasia ( $\mathrm{I}=$ mild; $\mathrm{II}=$ moderate; $\mathrm{III}=$ severe) by two pathologists who were blinded to a subject's smoking history. The results were compared and the case was enrolled only if the interpretation was the same. The cases showing regular SM + dysplasia were considered as dysplasias. Given that in the high grade of dysplasia it is usually easier to find a significant p53positivity, the biopsy with the highest grade of atypia was chosen to perform immunohistochemistry for $\mathrm{p} 53$.

The histological criteria used to classify progenitor lesions have been described by WHO [27]. SM: areas of bronchial mucosa exhibiting replacement of the ciliated respiratory epithelium by mature or immature stratified squamous epithelium which lacks cytological atypia. The basal cell layers is generally well defined and uniform. Bronchial dysplasia: areas in which the metaplastic squamous epithelium exhibits mild to marked nuclear atypia and an increased nucleus: cytoplasma ratio. The organization of the basal layer is disrupted, mitotic figures are increased and often present above the basal layer.
Immunohistochemistry for p53 protein. Sections $(3 \mu \mathrm{m})$ of routinely processed specimens for each case, cut onto coated slides, were dewaxed in xylene and rehydrated by passing through a graded series of ethanol concentrations ending with deionized distilled water. After rinsing in 0.05 $\mathrm{M}$ phospate-buffer saline (PBS), the slides were washed in citrate buffer $(\mathrm{pH} 6)$ and treated in a microwave oven using 750 Watt power for $15 \mathrm{~min}(3 \times 5 \mathrm{~min})$. After complete cooling the slides were incubated in $0.1 \%$ sodium azide containing $0.3 \%$ hydrogen peroxide for $15 \mathrm{~min}$ to quench the endogenous peroxidase, and then were treated with $3 \%$ normal goat serum for 15 min to block non-specific binding. The primary monoclonal antibody (p53- D07, BIOOPTICA, Milan, Italy) was then applied to the sections at a dilution of $1: 100$ and incubated for $1 \mathrm{~h}$ at $37^{\circ} \mathrm{C}$. After three washes in PBS, slides were treated with biotinilated immunoglobulin (Ig)G-anti-rabbit for $30 \mathrm{~min}$ at room temperature. After two washes in PBS, peroxidase-conjugated streptavidin was applied for $15 \mathrm{~min}$ at room temperature. To develop peroxidase activity, a filtered solution of 5 $\mathrm{mg}$ of 3-3'diaminobenzidine tetrahydrochloride (15KP500 BIO-OPTICA), dissolved in $10 \mathrm{~mL}$ of tris buffer $(0.05 \mathrm{M}$, $\mathrm{pH}$ 7.6) and $0.03 \mathrm{H}_{2} \mathrm{O} 2$, was used. Mayer haematoxylin was employed to counterstain the slides. Negative control slides, to which normal rabbit serum instead of primary antibody was applied, were included in each staining. Unequivocal nuclear staining was the criterion for a positive reaction: cytoplasmic staining alone was considered negative for $\mathrm{p} 53$.

Evaluation of immunohistochemistry. To assess p53 staining, sections for each case were independently scored by both pathologists and the results were compared. Scoring of p53 immunoreactivity was done semiquantitatively (the number of p53-positive nuclei was counted and expressed as a percentage of all nuclei of the lesion) and, divided into four groups: $0=$ negative; $+=1-10 \%-++=10-50 \% ;+++$ $>50 \%$.

Subjects. Finally, 22 subjects (7 females and 15 males. mean age $61.6 \pm 7.8 \mathrm{yrs}$ ), current smokers for about 30 packyrs with at least a bronchial dysplastic lesion but without a detectable lung tumour were enrolled, on the basis of the data reported by SACCOMANNO et al. [4] concerning the delay of development from mild/moderate atypia to invasive carcinoma, into a minimum of 4 yrs of clinical and radiological follow-up study to control the possible development of LC.

\section{Analysis}

Age and tobacco consumption (pack-yrs) of the subjects were expressed as mean \pm SD. Comparisons between the means of the subjects with dysplasia showing p53-positivity and dysplasia p53-negative and with or without cancer were made by Student's unpaired t-test. Categorical variables were expressed by contingency tables, and Chisquared test was used for determining the significance of associations. Values of $\mathrm{p}<0.05$ were considered significant. Relative risk for p53 positivity with $95 \%$ confidence intervals (95\% CIs) was used to measure the strength of the association between the risk factor and illness. 
Table 1. - Patients' clinical characteristics and p53 status

\begin{tabular}{lcc}
\hline & \multicolumn{2}{c}{ p53 status } \\
\cline { 2 - 3 } Clinical characteristics & Negative & Positive \\
\hline Age yrs & $60 \pm 8$ & $63 \pm 8^{+}$ \\
Male & 8 & 7 \\
Female & 5 & 2 \\
Smoking pack-yrs & $34 \pm 6$ & $53 \pm 14^{++}$ \\
Grade of dysplasia & $5(62.5)$ & $3(37.5)$ \\
I & $6(60)$ & $4(40)$ \\
II & $2(50)$ & $2(50)$ \\
III & $13(60)$ & $9(40.9)$ \\
Total & & \\
Malignancy within the & 1 & 6 \\
follow-up: 4yrs & 2 & 0 \\
SQCC & 0 & 1 \\
Adenocarcinoma & $3(30)$ & $7(70)$ \\
SCLC & & \\
Total & & \\
\hline
\end{tabular}

Values represent mean $\pm \mathrm{SD}$ or $\mathrm{n}(\%) ;{ }^{+}: \mathrm{p}=0.3 ;{ }^{++}: \mathrm{p}=0.001$; SQCC: squamous cell carcinoma; SCLC: small cell lung carcinoma; $\mathrm{n}=22$.

\section{Results}

Table 1 summarizes the clinical characteristics, the smoking habit, the grade of dysplasia, the p53 status in the dysplastic lesions at the time they were detected and in the corresponding tumours, and the malignancy at the end of the follow-up of the patients studied (a minimum of 4 yrs of follow-up for each patient).

Table 2 displays the characteristics of the patients who developed a tumour and the period between first systematic bronchoscopic sampling and the diagnosis of lung cancer ("latency time"). Carcinoma was detected in 10 $(45 \%)$ of the 22 patients and SQCC was the most frequent type of tumour associated with dysplastic lesions (7 SQCC, 2 adenocarcinomas and 1 small cell lung carcinoma (SCLC)). In 5 of these 10 cases, the tumour was diagnosed within a year after dysplasia was detected (synchronous), the remaining 5 after one year (metachronous).

The mean age was not significantly different $(\mathrm{p}=0.3)$ between the subjects with p53-positive lesions ( $63 \pm 8 \mathrm{yrs})$ and the subjects without $\mathrm{p} 53$-positivity ( $60 \pm 8 \mathrm{yrs})$ and was not different $(\mathrm{p}=0.2)$ between the subjects who developed

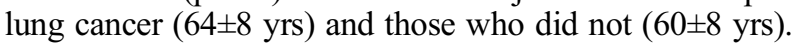

Table 3. - Grade of dysplasia and malignancy

\begin{tabular}{lrcc}
\hline & & Malignancy & No malignancy \\
\hline I & $8(36)$ & $2(25)$ & $6(75)$ \\
II & $10(45)$ & $5(50)$ & $5(50)$ \\
III & $4(18)$ & $3(75)$ & $1(25)$ \\
\multicolumn{2}{l}{ Total 22} & $10(45)$ & $12(55)$ \\
\hline
\end{tabular}

Values are presented as $\mathrm{n}(\%) \cdot \mathrm{p}=0.3$.

The average tobacco consumption of the subjects was high ( $42 \pm 14$ pack-yrs) and the amount of lifetime cigarette consumption seems to be a factor closely related to p53 overexpression and cancer. In fact, the subjects with p53positivity smoked more than the subjects with p53-negativity (mean pack-yrs $53 \pm 14$ and $34 \pm 6$ respectively) and the difference was statistically significant $(\mathrm{p}=0.0003)$. The subjects with cancer at the end of the follow-up smoked more than the subjects without cancer $(49 \pm 17$ and $36 \pm 8$ pack-yrs) and the difference was statistically significant $(\mathrm{p}=0.03)$.

Of the twenty-two dysplastic lesions, 8 (36\%) were labelled as grade I, $10(45 \%)$ as grade II, and $4(18 \%)$ as grade III (table 3 ). A malignancy occurred in 2 of $8(25 \%)$ patients with grade I dysplasia, in 5 of $10(50 \%)$ with grade II dysplasia and in 3 of 4 (75\%) with grade III dysplasia (table 3). The relationship between grade of dysplasia and malignancy was not statistically significant $(\mathrm{p}=0.3)$, although a positive association seems to exist between these variables.

Nine (41\%) of the 22 lesions showed p53-positivity. Cells were counted as positive if they showed a strong nuclear staining. Dysplasia was considered positive for $\mathrm{p} 53$ immunostaining even if less than $10 \%$ of nuclei were stained. Two types of p53 immunostaining were found in the dysplastic lesions: scattered, isolated p53-positive cells and clusters of p53-positive cells. Normal bronchial epithelium was completely negative for p53 immunostaining. SM lesions without atypia, in which unequivocal nuclear p53 staining was not detected, are not represented in this paper.

Positive p53 immunostaining was seen in $37 \%$ of grade I dysplasias (3/8), 40\% of grade II dysplasias (4/10) and $50 \%$ of grade III dysplasias (2/4) (table 1$)$. At the end of the follow-up, 6 SQCC and 1 SCLC were detected in 7/9

Table 2. - Characteristics of the patients with a tumour

\begin{tabular}{|c|c|c|c|c|c|c|c|}
\hline Patient & Sex & $\begin{array}{l}\text { Age } \\
\text { yrs }\end{array}$ & $\begin{array}{l}\text { Smoking } \\
\text { pack-yrs }\end{array}$ & $\begin{array}{c}\text { Dysplasia } \\
\text { grade }\end{array}$ & $\begin{array}{c}\text { p53 } \\
\text { expression }\end{array}$ & Diagnosis & $\begin{array}{l}\text { Months } \\
\text { after biopsy }\end{array}$ \\
\hline 1 & $\mathrm{~F}$ & 61 & 28 & I & - & Adenocarcinoma & 31 \\
\hline 2 & $\mathrm{~F}$ & 70 & 32 & II & - & Adenocarcinoma & 8 \\
\hline 3 & M & 67 & 42 & III & - & SQCC & 36 \\
\hline 4 & M & 78 & 75 & $\mathrm{I}$ & ++ & SQCC & 30 \\
\hline 5 & M & 68 & 42 & II & ++ & SQCC & 18 \\
\hline 6 & $\mathrm{~F}$ & 51 & 54 & II & ++ & SQCC & 5 \\
\hline 7 & M & 68 & 75 & II & ++ & SQCC & 16 \\
\hline 8 & $\mathrm{~F}$ & 55 & 40 & II & +++ & SQCC & 5 \\
\hline 9 & M & 59 & 35 & III & ++ & SCLC & 10 \\
\hline $\begin{array}{l}10 \\
\text { mean } \pm \text { SD }\end{array}$ & M & $\begin{array}{c}60 \\
64 \pm 8\end{array}$ & $\begin{array}{c}60 \\
49 \pm 17\end{array}$ & III & +++ & SQCC & 6 \\
\hline
\end{tabular}

M: male; F: female; SQCC: squamous cell carcinoma; SCLC: small cell lung carcinoma. -: negative; +: 1-10\%; ++: 10-50\%; +++: $>50 \%$ of nuclei positive. 
Table 4. - p53 immunoreactivity in dysplasia and malignancy

\begin{tabular}{|c|c|c|c|c|c|c|}
\hline \multirow{2}{*}{$\begin{array}{l}\text { Grade of } \\
\text { dysplasia }\end{array}$} & \multicolumn{3}{|c|}{ p53-positive } & \multicolumn{3}{|c|}{ p53-negative } \\
\hline & Total & Malignancy & No malignancy & Total & Malignancy & No malignancy \\
\hline I 8 & 3 & $1(33)$ & $2(67)$ & 5 & $1(20)$ & $4(80)$ \\
\hline II 10 & 4 & $4(100)$ & 0 & 6 & $1(17)$ & $5(83)$ \\
\hline III 4 & 2 & $2(100)$ & 0 & 2 & $1(50)$ & $1(50)$ \\
\hline Total 22 & 9 & $7(78)$ & $2(22)$ & 13 & $3(23)$ & $10(77)$ \\
\hline
\end{tabular}

Values are presented as $\mathrm{n}(\%) . \mathrm{p}=0.01$.

(78\%) patients with p53-positive dysplastic lesions, whereas 1 SQCC and 2 adenocarcinomas were diagnosed in $3 / 13(23 \%)$ patients with p53 negative dysplastic lesions (tables 2 and 4). p53-positive dysplasia was found especially throughout the right bronchial tree. LC was diagnosed in the same area of the previously detected p53-positive dysplasia.

The positive predictive value of $\mathrm{p} 53$ immunostaining for lung cancer was $78 \%$ (table 4 ). The negative predictive value of p53 was $77 \%$ (table 4). The association between p53 immunoreactivity and malignancy was statistically significant $(\mathrm{p}=0.01)$. The relative risk for cancer to develop in the p53 positive subjects was 3.37 (CIs 1.31-8.65).

LC occurred in all seven patients with dysplastic lesions showing $>10 \%$ p53 positive nuclei (positive predictive value $=100 \%$ ) (table 2 ; fig. 1$)$. In these lesions, the pattern of immunoreactivity, more indicative of $\mathrm{p} 53$ gene mutation, was characterized by clusters of positive nuclei (11$60 \%$ ) in the basal and suprabasal areas. In 2 of 3 p53positive grade I dysplasias, the pattern of immunoreactivity was restricted to scattered, isolated cells, located predominantely in the lower layers (these lesions showed $<5 \%$ p53 positive nuclei) (fig. 2). Of these two p53positive cases, one had interstitial fibrosis and the other had chronic obstructive pulmonary disease (COPD).

\section{Discussion}

As far as the authors' know, this is one of the first attempts to investigate the predictive value of immunohistochemical overexpression of $\mathrm{p} 53$ protein for the occurrence of LC by collecting bronchial dysplastic lesions in

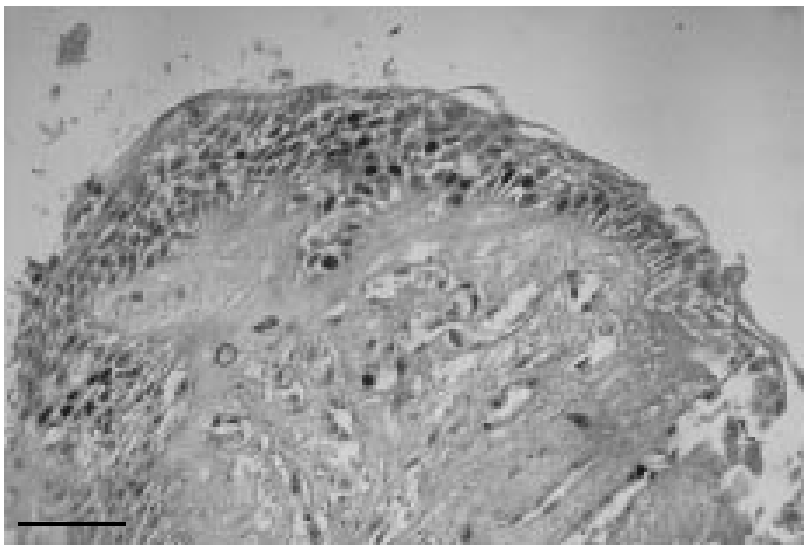

Fig. 1. - Bronchial biopsy containing a dysplastic lesion stained immunohistochemically for p53. The p53 score was $>50 \%$. (Internal scale bar $=80 \mu \mathrm{m}$.) subjects already at risk for developing LC, but with no detectable tumour, and following them over a period of at least four years.

The study shows that seven of nine subjects with p53 positive dysplasia developed a lung cancer within the follow-up period (positive predictive value $=78 \%$ ) whereas only three p53 negative subjects developed a tumour (negative predictive value $77 \%$ ). In the group with more than $10 \%$ positive nuclei, the positive predictive value was $100 \%$. The association between p53 positivity and the occurrence of malignancy was statistically significant $(\mathrm{p}=$ 0.01 ). The relative risk for cancer to develop in the $\mathrm{p} 53$ positive subjects is estimated at a 3.37-fold increase over the 553 negative subjects. The association between grade of dysplasia and malignancy was not significant $(\mathrm{p}=0.3)$, although a high grade of dysplasia seems to have a positive correlation with the occurrence of malignancy. The amount of lifetime cigarette consumption was the only factor related to $p 53$ mutations and cancer $(p=0.0003$ and $p=0.03$, respectively), These data support the conclusion that $\mathrm{p} 53$ overexpression in bronchial dysplastic areas is a more predictive marker of the development of LC than dysplasia.

Immunohistochemical overexpression of p53 protein is currently used as indicator of p53 mutation especially if p53-positive nuclei occur in clusters in the basal and suprabasal areas in premalignant lesions $[15,19,21,28$ 29 ], whereas the presence of a few scattered immunoreactive nuclei is probably due to a transient elevation of the wild-type p53 protein concentration [20, 21, 28, 30, 31]. Obviously, immunohistochemistry cannot detect such mutations that lead to low levels of protein or no protein at all. Therefore, a weak or no p53 cellular staining may also indicate a mutated p53 gene [32].

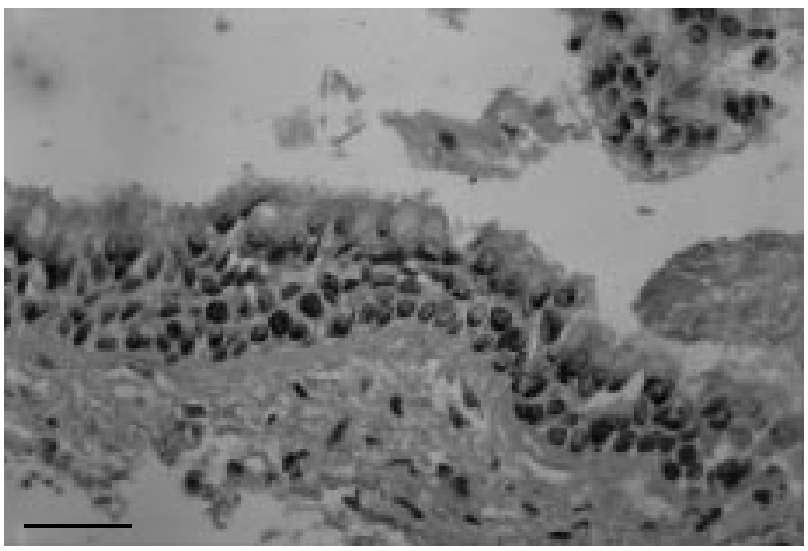

Fig. 2. - Bronchial biopsy containing a dysplastic lesion in which only a few nuclei were positive for p53 immunostaining. The p53 score was $5 \%$. (Internal scale bar $=50 \mu \mathrm{m}$.) 
In the present study, in which a small series of bronchial dysplasias were investigated because cases were extremely selected and technical problems related to the small size of bronchial specimens, p53 immunoreactivity was found in 9 of $22(41 \%)$ dysplastic lesions: $37 \%$ of mild dysplasia, $40 \%$ of moderate dysplasia and $50 \%$ of severe dysplasia. There was an increasing frequency of $\mathrm{p} 53$ protein accumulation starting with mild dysplasia, although the frequency in mild dysplasia was higher than in previous reports. This is mainly due to the small series investigated. Moreover, two mild dysplastic lesions labelled as p53-positive showed only isolated p53-immunoreactive cells dispersed along the basal area and they were found in two subjects with benign disease who did not develop LC within the follow-up, so the case that may be considered really significant is 1 out $8(12.5 \%)$. Nevertheless, being the follow-up time limited to 4 years, it is possible that they may develop LC later, but it is remarkable to consider that carcinoma occurred within the follow-up in all seven subjects with lesions showing definite clusters of p53-positive nuclei. This allow us to support the hypothesis that cells with mutant p53 genes seem to acquire a selective growth advantage leading to rapid selection of malignant clones [30, 33]. Of these seven lung cancers, six were SQCC that turned out to be p53-positive, whereas three p53-negative subjects developed a p53-negative tumour (1 SQCC and 2 adenocarcinomas) (tables 1 and 4).

These data confirm the results reported by other studies supporting a multistage model for SQCC in which genetic damage to the p53 gene occurs before the onset of invasion [20-22, 25, 26]. Rusch et al. [25] have reported that p53 staining was not seen in any of the bronchial lesions associated with invasive tumours of histologies other than SQCC, even though the tumour was p53 positive, concluding that abnormalities of p53 expression may be a late event in the development of nonsquamous carcinomas [25]. In a paper by BramBilla et al. [30], a link between preinvasive bronchial lesions and nonsquamous cancers has been established, even though squamous carcinoma was the most frequent type of LC associated with preinvasive lesions. The present results compare well with the observations of previous studies [21, 22, 26, 34].

During the course of this prospective study, two authors have reached the same results. BOERs et al. [35] have provided evidence, from a retrospective study on a series of 51 bronchial dysplasia of patients with or without lung cancer, that $\mathrm{p} 53$ positivity had a higher predictive value for synchronous lung cancer than the high grade of dysplasia. Boers et al. [35], in contrast with the present results, reported that $\mathrm{p} 53$ seems to identify patients at risk for LC irrespective of the type of the pattern of p53 immunoreactivity. However, because the present study referred to fewer cases, with a shorter follow-up time, is not necessarily at variance with these data.

More recently, BRAMBILla et al. [30] have highlighted the importance of studying the overexpression of p53 from hyperplasia to carcinoma in situ in the largest group of patients with and without LC so far analysed, the high predictive value of $\mathrm{p} 53$ for progression to invasion whenever p53 immunostaining is found in preinvasive lesions showing definite clusters of p53-positive cells, also suggesting that $\mathrm{p} 53$-negative lesions could progress less rapidly through invasion. BramBiLla et al. [30] used 20 patients with no cancer history as a control group in which 10 patients were nonsmokers, dysplasias were rare and there was no case of p53-positivity in preinvasive lesions [30]. Our study differs in that biopsies were collected in heavy smokers and only dysplastic lesions were selected to perform immunohistochemistry for p53 and, besides, the follow-up time was longer.

In conclusion, our findings provide evidence that screening early bronchial lesions for p53 mutations may be of help for the early diagnosis of lung cancer, at least of SQCC, and may facilitate the detection of occult tumours. As malignant transformation seems to result from activation of different mechanisms, the use of additional biomarkers could enhance the diagnostic possibilities offered by $\mathrm{p} 53$ immunohistochemistry $[25,30,35]$. Patients with preinvasive bronchial lesions positive for markers of cancer progression, especially for $\mathrm{p} 53$, should represent targets for interventional strategies designed to interrupt premalignant progression.

\section{References}

1. Parkin DM, Pisani P, Ferlay J. Estimates of the worldwide incidence of eighteen major cancers in 1985. Int J Cancer 1993; 54: 594-606.

2. Petty TL. Lung cancer screening comp. Therapy 1995; 21: 432-437.

3. Peters EJ, Morice R, Benner SE, et al. Squamous metaplasia of the bronchial mucosa and its relationship to smoking. Chest 1993; 103: 1429-1432.

4. Saccomanno G, Archer VE, Auerbach O, Saunders RP, Brennan LM. Development of carcinoma of the lung as reflected in exfoliated cells. Cancer 1974; 33: 256-270.

5. Ihde DC, Minna M. Non-small cell lung cancer. Part 1: biology, diagnosis and staging. Curr Probl Cancer 1991; 15: 65-147.

6. Damber L, Larsson L. Smoking and lung cancer with special regard to type of smoking and type of cancer. A case control-study in north Sweden. Cancer 1986; 53: 673-681.

7. Lee JS, Lippman SM, Bennar SE, et al. Randomized placebo-controlled trial of isotretinoin in chemoprevention of bronchial squamous metaplasia. J Clin Oncol 1994; 12: 937-945.

8. Sawyer RW, Hammond WG, Teplitz RL, Benfield JR. Regression of bronchial epithelial cancer in hamsters. Ann Thorac Surg 1993; 56: 74-78.

9. Fearon ER, Vogelstein B. A genetic model for colorectal turnorigenesis. Cell 1990; 61: 759-767.

10. Minna JS. The molecular biology of lung cancer pathogenesis. Chest 1993; 103 (Suppl. 4): 449-456.

11. Chang F, Syrjanen S, Tervahoute A, Syrjanen K. Tumorigenesis associated with the $\mathrm{p} 53$ tumour suppressor gene. Br J Cancer 1993; 68: 653-661.

12. Miller C, Mohands T, Wolf D, Prokocimer M, Rotter V, Koeffler PH. Human p53 localized to a short arm of chromosome 17. Nature 1986; 319: 783-784.

13. Levine AJ, Perry ME, Chang A, et al. The 1993 Walter Hubert Lecture: The role of the p53 tumour-suppressor gene in tumorigenesis. Br J Cancer 1994; 69: 409-416.

14. Hollstein M, Sidronsky D, Vogelstein B, Harris CC. p53 mutations in human cancers. Science 1991; 253: 49-53.

15. Iggo R, Gatter K, Bartek J, Lane D, Harris AL. Increased expression of mutant forms of p53 oncogene in primary lung cancer. Lancet 1990; 335: 675-679.

16. Klein N, Vignaud JM, Sadmi M, et al. Squamous 
metaplasia expression of proto-oncogenes and p53 in lung cancer patients. Lab Invest 1993; 68: 26-32.

17. Brambilla E, Brambilla C. p53 and lung cancer. Pathol Biol 1997; 45: 852-863.

18. Sozzi G, Miozzo M, Donghi R, et al. Deletions of $17 \mathrm{p}$ and p53 mutations in preneoplastic lesions of the lung. Cancer Res 1992; 52: 6079-6082.

19. Sundaresan V, Ganly P, Hasleton P, et al. p53 and chromosome 3 abnormalities, characteristic of malignant lung tumours, are detectable in preinvasive lesions of the bronchus. Oncogene 1992; 7: 1989-1997.

20. Nuorva K, Soini Y, Kamel D, et al. Concurrent p53 expression in bronchial dysplasias and squamous cell lung carcinomas. Am J Pathol 1993; 142: 725-732.

21. Bennett WP, Colby TV, Travis WD, et al. p53 protein accumulates frequently in early bronchial neoplasia. Cancer Res 1993; 53: 4817-4822.

22. Hirano T, Franzen B, Kato H, Ebihara Y, Auer G. Genesis of squamous cell lung carcinoma. Sequential changes of proliferation, DNA ploidy, and p53 expression. Am J Pathol 1994; 144: 296-302.

23. Bennett WP, Hollstein MC, Metcalf RA, et al. P53 mutation and protein accumulation during multistage human esophageal carcinogenesis. Cancer Res 1992; 52: 60926097.

24. Suzuki H, Takahashi T, Kuroishi T, et al. p53 mutations in non-small cell lung cancer in Japan: association between mutations and smoking. Cancer Res 1992; 52: 734-736.

25. Rusch V, Klinestra D, Linkov I, Dmitrovosky E. Aberrant expression of $\mathrm{p} 53$ or the EGFR is frequent in early bronchial neoplasia, and coexpression precedes squamous cell carcinoma development. Cancer Res 1995; 55: 13651372.
26. Zheng J, Shu Q, Li ZH, Tsao J-L, Weiss LM, Shibata D. Patterns of p53 mutations in squamous cell carcinoma of the lung. Acquisition at relatively early age. Am J Pathol 1994; 145: 1444-1449.

27. Shisomato Y, Sobin LH, Spencer H, Yesner R. The World Health Organization Histological Typing of Lung Tumors. 2nd edn. Am J Clin Pathol 1982; 77: 123-136.

28. Brambilla E, Gazzeri S, Moro D, et al. Immunohistochemical study of p53 in human lung carcinomas. $A m J$ Pathol 1993; 143: 199-210.

29. Brambilla E, Negoescu A, Gazzeri S, et al. Apoptosis related factors $\mathrm{p} 53, \mathrm{Bcl} 2$ and $\mathrm{Bax}$ in neuroendocrine lung tumors. Am J Pathol 1996; 149: 1941-1952.

30. Brambilla E, Gazzeri S, Lantuejoul S, et al. p53 mutant immunophenotype and deregulation of $\mathrm{p} 53$ transcription pathway (Bcl2, Bax, and Wafl1) in precursor bronchial lesions of lung cancer. Clin Cancer Res 1998; 4: 16091618.

31. Winford-Thomas D. p53 in tumour pathology: we can trust immunochemistry? J Pathol 1992; 166: 329-330.

32. Gazzeri S, Brambilla E, Caron de Fromentel C, et al. p53 genetic abnormalities and myc activation in human lung carcinoma. Int J Cancer 1994; 58: 24-32.

33. Lane DP. p53, guardian of the genoma. Nature 1992; 358: 15-16.

34. Walker C, Robertson LJ, Myskow MW, Pendleton N, Dixon GR. p53 expression in normal and dysplastic epithelium and in lung carcinomas. Br J Cancer 1994; 70 : 297-303.

35. Boers JE, Ten Velde GPM, Thunnissen FBJM. p53 in squamous metaplasia: a marker for risk of respiratory tract carcinoma. Am J Respir Crit Care Med 1996; 153: 411416. 